\title{
O futuro do presente: acervos fotográficos diante do horizonte digital
}

\author{
Ricardo Mendes ${ }^{1}$ \\ Centro Cultural São Paulo/ \\ Divisão de Pesquisas
}

RESUMO: $\bigcirc$ cotidiano de trabalho de técnicos, pesquisadores e consulentes nos principais acervos fotográficos brasileiros nos últimos 10 anos vem se modificando, em ritmo desigual, com alterações profundas causadas por uma revitalização ampla de recursos humanos e técnicos, que cria lentamente um contexto novo de ação. O presente ensaio procura estimular a reflexão e debate sobre as implicações e desdobramentos desse processo enfocando um aspecto em particular: a introdução do gerenciamento de dados informatizado e a presença da imagem digital.

PALAVRAS-CHAVES: Fotografia. Imagem digital. Informatização de acervos. Gerenciamento de dados iconográficos. Banco de dados iconográficos. Interfaces de busca.

ABSTRACT: In the last 10 years, the daily routine of technicians, researchers and consultants in the main photographic collections in Brazil has been changing, at unequal pace, bringing deep transformations caused by the wide revitalization of human resources and technicians, which slowly builds up a new context for action. The present essay seeks to stimulate the reflection and debate about the implications and developments of this process, focusing on one particular aspect: the introduction of digitalized data management and the presence of the digital image.

KEYWORDS: Photography. Digital Image. Digitalisation of Collections. Managing Iconographic Data. Iconographic Database. Search Interfaces.

\author{
1. Ricardo Mendes é pes- \\ quisador em História da \\ Fotografia, doutorando em \\ História Social pela FFLCH- \\ USP e coordenador do si- \\ te FotoPlus (http://www \\ fotoplus.com/database). \\ Atua desde 1985 no Cen- \\ tro Cultural São Paulo, na \\ Divisão de Pesquisas, co- \\ mo coordenador da Equi- \\ pe Técnica de Pesquisas \\ em Fotografia. Sobre os te- \\ mas da interface arte e fo- \\ tografia e a historiografia \\ brasileira, publicou os en- \\ saios: Para que servem as \\ coleções (fotográficas)? \\ In: Fotografias no acervo \\ do Museu de Arte Moder- \\ na de São Paulo, MAM-SP \\ 2002 e Once upon a time: \\ uma história da História da \\ Fotografia brasileira.Anais \\ do Museu Paulista, Mu- \\ seu Paulista-SP, 2004. Parti- \\ cipa ainda, entre outras, \\ nas seguintes publica- \\ ções: São Paulo de Lévi- \\ Strauss Cia. das Letras, São \\ Paulo, 1996, Imagens de \\ São Paulo: Gaensly no \\ acervo da Light (1899- \\ 1925), pela FPHESP, 2001, \\ Retratos do imaginário \\ de São Paulo:fotógrafos e \\ personagens, Formarte, \\ 2001 e São Paulo anos 20: \\ andar, vagar, perder-se, \\ Melhoramentos, 2003.
}


2. Este ensaio foi apresentado em sua versão original como comunicação no evento Sistema Municipal de Museus da Cidade de São Paulo:enfoques temáticos, metodologias e pro cessos de trabalbo museológico, realizado no Solar da Marquesa de Santos (18 a 20/5/2004), sob o título: O futuro do presente: ob servações sobre a informação digital em acervos paulistanos. Essa comunicação foi dedicada à equipe do Centro de Conser vação e Preservação Fotográfica da Funarte, idealizado por Solange Zuñiga há 20 anos e concretizado com a participação-chave de Sérgio Burgi em 1985 centro que por meio de duas gerações de pesquisadores e técnicos dedicase à pesquisa e ao treina mento especializado. fundamental que o centro conte com todo apoio para sua reinvenção neste momento particular que aponta para extremos opostos: primeiro, a aplicação e uso da imagem numérica como instrumento de trabalho e, igualmente, como objeto de preservação; e, segundo, a necessidade contínua de pesquisa sobre a imagem de base química, cujos custos materiais e humanos para preservação serão mais elevados e prementes.

3. O conceito de imagens numéricas parece ser mais abrangente e adequado em vez de imagens técnicas (geradas por apare lhos) ou digitais, por apontar para o horizonte de trabalho, que se delineia, reunindo registros captados por câmeras, escaneados ou construções virtuais. No entanto, ao longo do texto será usual a referência a imagens digitais nessa mesma acepção.
Preâmbulo²

A questão de como o desenho de um instrumento orienta e determina em certa medida o seu próprio uso não é nova. No entanto, na rotina diária, ela permanece sempre em plano profundo. No universo das Ciências Humanas, muitas vezes na precariedade de determinados campos de atuação, tal questão fica, quando muito, adiada sob a pressão das necessidades imediatas.

A proposta deste ensaio é discutir algumas implicações a médio prazo causadas pela contínua (ainda que irregular) presença de aplicações digitais no sentido mais amplo do termo, estendendo-se da automatização de sistemas de gerenciamento de acervos ao uso de imagens numéricas ${ }^{3}$ - no cotidiano dos acervos documentais históricos.

Esta proposta procura tirar proveito da sistemática adotada pela seção Debates que, por meio da circulação de um ensaio entre um conjunto de pesquisadores e técnicos relacionados ao tema, busca reunir comentários e colaborações. Considerando-se o recorte temático, o desencadeamento dessa sistemática de comunicação pode atender a uma das primeiras preocupações: a de permitir o registro de questões advindas desse processo de alterações tecnológicas em acervos brasileiros, certamente expectativas e dúvidas que poderiam se perder a curto prazo.

$\bigcirc$ presente ensaio procura fazer um balanço do tema discutindo experiências desenvolvidas nas duas últimas décadas em coleções fotográficas paulistanas sob guarda institucional. Embora sejam comentados projetos de naturezas diversas, o conjunto em sua diversidade permite levantar uma série de questões conceituais e metodológicas relativas a etapas diversas como planejamento, manutenção e treinamento voltado para aplicações digitais nesse contexto.

Nossa expectativa é que a leitura do ensaio estimule os participantes do círculo de discussão a pensar criticamente suas experiências como membros de instituições com atividades similares ou como usuários desses acervos documentais. Na elaboração da relação de pesquisadores e técnicos convidados a participar da seção Debates, procurou-se garantir não só a presença de profissionais de campos como História, Fotografia e Biblioteconomia, mas ainda técnicos de setores diretamente relacionados como analistas de sistemas e administradores, e, indo mais além, convidando especialistas dos segmentos de design gráfico e de novas mídias de comunicação.

A questão central

Como o horizonte digital acelera essa ação "natural" de modelagem do passado que toda coleta e organização de dados e objetos, informações e documentos implica, é, em resumo, a questão central. Quão graves são seus 
desdobramentos num contexto como o nosso em que determinados trabalhos institucionais encontram-se ou em situação de implantação (como os acervos fotográficos) e/ou sob contínuas restrições de orçamento e de continuidade administrativa?

Outro modo de formular essa pergunta, praticamente invertendo o ponto de partida, seria pensar como os instrumentos de pesquisa na era digital poderiam restringir ou orientar - para o bem e para o mal - a produção documental e reflexiva, determinando as historiografias possíveis.

Algumas perspectivas para estabelecer uma "conversação" podem ser apontadas como forma de estímulo para os participantes:

1. Embora o ensaio enfoque o campo dos acervos fotográficos, interessa em especial discutir experiências propostas sobre outros gêneros de documentos que não sejam o livro: registros sonoros, imagens em movimento e novas mídias como a Internet.

2. Buscam-se o registro de experiências, relatos sobre ganhos e perdas (em especial, os insucessos), descobertas e estratégias adotadas. Enfim, comentários sobre ações desenvolvidas por gestores, teóricos nos diversos campos e usuários, na esfera nacional ou não.

3. As ações desenvolvidas tiveram lugar como mera transposição digital de sistemas existentes? Nesse caso, quais os parâmetros de avaliação propostos? Qual o grau de satisfação no atendimento das expectativas?

4. Quais foram os modelos referenciais adotados nas experiências relatadas? Que limites e adequações estratégicas tiveram de ser estabelecidos em suas implementações?

5. Que ações paralelas foram desenvolvidas? Por exemplo, controle de descritores, implementação de vocabulários controlados. Sabendo que no campo da fotografia, os projetos desenvolvidos abordam coleções voltadas para a documentação urbana e o retrato, foi possível rever os descritores (de conteúdo ou de descrição visual), em especial considerando a adequação perante a abrangência temporal?

6. No campo do design, quais experiências em interfaces gráficas, em especial via Internet, foram realizadas? Como modelo instigador, apontamos a obra apresentada por Gavin Adams na mostra Olho cíclico, em que um ícone mapeia a coleção de retratos do estúdio de Militão Augusto de Azevedo usando como elemento ordenador uma tipologia de poses. Os sistemas em desenvolvimento não deveriam voltar-se para um número maior de usuários e discutir o desenho de novas intermediações entre esses públicos e as bases de dados por meio de mecanismos distintos de busca? 
A organização documental e as estratégias de interpretação e classificação permitem antever como diversos segmentos sociais delineiam olhares das histórias do futuro. Nesse quadro são ações decisivas as formas pelas quais se disponibiliza o acesso a certos conjuntos documentais ou as prioridades dadas para tratamento e pesquisa.

Este breve ensaio, na verdade um rascunho de projeto a ser elaborado, procura apresentar como colaboração uma visão retrospectiva sobre a presença da informação digital no âmbito de acervos fotográficos paulistanos no campo da memória. Sem ambicionar, contudo, um quadro completo, busca apontar ocorrências de maior relevância.

Essa visão é elaborada a partir de uma perspectiva peculiar. Tal síntese é feita não pela perspectiva do trabalhador atuante nesses arquivos, mas a partir da experiência como pesquisador em História da Fotografia, como usuário especializado dessas fontes documentais. Essa peculiaridade não constitui um ponto de partida privilegiado, apenas uma possibilidade.

Este relato, certamente, reflete uma parcialidade incontornável. $\bigcirc$ conhecimento do usuário em particular sobre as instituições e o processo de constituição e organização de seus acervos atenua (e compensa, ironicamente) as falhas dos sistemas de atendimento. Em outras palavras, se a experiência pessoal permite contornar dificuldades, ela eclipsa em parte a percepção de falhas, ainda que o padrão de exigência (e interlocução) do usuário possa ser mais abrangente.

A abordagem a ser desenvolvida procura observar a presença nesses ambientes de sistemas de informação digital numa acepção mais abrangente do que o simples uso da imagem numérica como material de trabalho. Procura entender a aplicação de tecnologia digital no conjunto maior das atividades dos arquivos e museus, da coleta à conservação, da catalogação à difusão.

Antecipadamente, seria relevante apontar que o desafio maior não é, no panorama brasileiro, de ordem técnica. Três décadas de atividade crescente do segmento estudado indicam que é o desafio administrativo o ponto de maior dificuldade de ataque. E deveria ser em associação a esse ponto que o aspecto tecnológico merece ser discutido.

Embora nos últimos 10 anos um número expressivo de técnicos tenha sido preparado para atuar nos mais diversos segmentos especializados de museus e arquivos, quase sempre sem um ensino formal específico, com formação usualmente resultante do esforço pessoal, poucas possibilidades têm surgido para garantir o aprimoramento dos responsáveis pelo gerenciamento dessas instituições.

Não se trata aqui de reivindicar a aplicação de uma cultura gerencial transferida pura e simplesmente de outros setores, da mera importação de ferramentas administrativas. Trata-se sim de apontar a necessidade de pesquisar e analisar experiências nessa direção ao longo das últimas décadas, reflexão 
essa que identifique estratégias de trabalho adotadas e seu alcance, permitindo a tomada de decisões e a monitoração dos seus resultados. Nesse quadro, são relevantes não só os exemplos bem-sucedidos, ainda que não duradouros, mas até mesmo estrondosos fracassos, cuja proposição e debate possam revelar novas perspectivas.

É importante lembrar que nesse aspecto têm sido raros entre nós os estudos de análise institucional. E, como todos sabem, são poucas as instituições que têm organizado e disponibilizado ao público, mais do que suas coleções, a própria memória de trabalho.

Estágios tecnológicos de ação

Procurando voltar ao tema, seria possível propor uma abordagem mais ampla: uma avaliação das tecnologias que dominam a rotina desses arquivos e museus por décadas. Espantosamente até pouco menos de 20 anos, a rotina de trabalho de nossas instituições detentoras de acervos de imagem pouco teria avançado no uso de técnicas apropriadas da biblioteconomia e da arquivística além do universo do "papel": fichas, catálogos...

Ao longo das décadas de 1970 e 1980 quando as instituições paulistanas nesse setor começam a tomar corpo, quase nenhum avanço tecnológico significativo parece ter ocorrido nas diversas etapas. Nem o uso das microformas parece ter tido qualquer relevância. Quando muito, registra-se o uso da xerografia como recurso emergencial. $E$, em muitos casos, nem isso.

Ainda assim, em tal universo tecnológico dominado por fichas de papel e cópias contatos, no ano de 1946, Gilberto Ferrez destacava em seu artigo - A fotografia no Brasil e um dos seus mais dedicados servidores: Marc Ferrez - a importância do serviço realizado por Benedito Junqueira Duarte na organização e processamento de imagens no âmbito do Departamento de Cultura, núcleo original do que seria a seção Arquivo de Negativos, ainda hoje em funcionamento na Secretaria Municipal de Cultura de São Paulo ${ }^{4}$.

À surpresa que podemos experimentar perante esse destaque já naquela época, conhecendo-se o quadro precário em que se encontravam as coleções de imagem mais de 30 anos depois, poderia ser acrescentada uma pergunta: qual seria o público de tal serviço?

Essa questão (na verdade uma provocação) procura apontar apenas para o fato que muitas das decisões tomadas nesse campo precedem, literalmente, uma demanda definida. E a necessidade de estabelecer um perfil de usuário e seus interesses nem sempre fica clara na rotina de trabalho, mas essa ideação dupla de serviços e públicos possíveis está permanentemente colocada e explica muito do sucesso (e parte do fracasso) dessas atividades.

quadro começaria a mudar a partir de meados da década de 1980. $\bigcirc$ uso da informação digital passa a ser cogitada aqui ou ali, ainda sob o domínio dos mainframes. Basta lembrar que, num contexto maior, data do 
início dessa década o processo, complicado e tortuoso, de informatização do sistema municipal de bibliotecas.

Entre 1980 e 1982, por exemplo, no Departamento de Patrimônio Histórico, em sua Divisão de lconografia e Museus (DIM), sob cuja guarda se encontra o Arquivo de Negativos, andamentos nesse sentido foram feitos entre a equipe e os analistas da Prodam, empresa que controlava todo o processamento de dados da prefeitura da cidade de São Paulo. Eles ocorreram em paralelo ao momento em que a equipe de fotógrafos e pesquisadores de diversas áreas técnicas englobadas pela DIM participava da mais abrangente e ambiciosa proposta realizada até então visando à implantação de um sistema de tratamento museográfico do acervo fotográfico. $\bigcirc$ conjunto de intervenções propostas, que seria reunido em 1983 no documento Anteprojeto de mudança estrutural da Divisão de lconografia e Museus, não foi implantado. Mas constituiu certamente para alguns de seus proponentes um importante momento de formação profissional.

Tal projeto apresentava alguns pontos falhos no que toca à catalogação ou ao tópico da pesquisa em todas as suas vertentes ao longo da rotina de funcionamento de um acervo, por exemplo. Nas reuniões de trabalho era evidente - despreparo da equipe, da qual eu participava, no que se referia à sistematização de informação, mas também ocorria um descompasso similar por parte do atendimento prestado pelos analistas que procuravam adaptar softwares voltados para outros usos, pouco adequados para uma recuperação ampla e flexível de informação.

Mas é necessário avançar no tempo. Dez anos depois, em 1991 , ganha forma na instituição mantida pelo Banco ltaú, ainda sob denominação de Instituto Cultural Itaú, a primeira ocorrência de uso relevante de tecnologia digital no âmbito em discussão: o Banco de Dados Itaú Cultural.

Embora o projeto inclua vários desdobramentos temáticos, é o núcleo dedicado à fotografia, e, em especial, à documentação urbana, que nos interessa avaliar. Constituía o projeto uma versão digital dos serviços oferecidos por acervos como o Arquivo de Negativos ou o Museu da Imagem e do Som, mas aqui predominava o aspecto referencial, destinado a usuários não especializados e estudantes do segundo e terceiro graus. Organizado ao redor de entes urbanos, termo que designava logradouros e regiões da cidade, o banco de dados gerenciava reproduções digitais, vindas de acervos e fontes diversas.

Além disso, o sistema de consulta, disponibilizado em conjuntos de terminais localizados em dois a três pontos na cidade de São Paulo, estava associado a um programa editorial voltado para a publicação de cadernos de referência que permitiam, num momento em que a Internet era apenas uma projeção distante, expandir o alcance daquele acervo virtual.

A introdução desse serviço, novo não apenas por constituir um banco referencial, mas por introduzir novas formas de consulta direta em monitores e logo depois possibilitar as primeiras experiências de impressão digital, merece ainda um estudo adequado. Para pesquisadores em atividade no período, o uso de terminais era uma experiência distinta do acesso a imagens em papel, 
muitas vezes uma forma pouco adequada ao uso numa primeira avaliação, mas para os usuários em geral, aparentemente representados por estudantes do segundo ciclo, o Banco de Dados Itaú Cultural era efetivamente a grande porta de entrada para o campo de estudo da imagem urbana.

$\bigcirc$ programa seria ampliado continuamente, sempre como base referencial, vindo a incorporar em 1998 o Setor História da Fotografia, disponibilizado no ano seguinte via Internet. No entanto, na passagem para este século, esses serviços foram desativados, dando lugar em 2001 à Enciclopédia de artes visuais Itaú Cultural, também de acesso virtual, mas de abrangência mais ampla e com tratamento genérico do que o tópico de nosso interesse.

Quase em paralelo, um processo de intervenção mais direta, mas também partilhando algo do gesto referencial, teria lugar no âmbito de uma instituição clássica: o Museu Paulista-USP. Nos primeiros anos da década de 1990, aquela instituição passa por um momento de renovação durante a gestão de Ulpiano Bezerra de Meneses. Entre as suas propostas, estava a criação de uma das mais ambiciosas bases para gerenciamento de imagem. Estruturadas ao redor de alguns vetores como memória urbana e espaço doméstico, entre outros, as bases propostas visavam a gerenciar não apenas o acervo da instituição, mas também em alguns momentos atuar como referencial a outras coleções. Implicava o projeto a aquisição de equipamentos de porte, com recursos então completamente novos e inimagináveis como disqueteiras automáticas de CD-ROMs.

projeto não se concretizou, mas certamente é fruto do longo e detalhado processo de pesquisa e planejamento daquela proposta a constituição do banco iconográfico hoje existente, possivelmente a mais antiga e extensa aplicação de sistema de gerenciamento de dados e imagem digital em acervos iconográficos paulistanos. $\bigcirc$ núcleo inicial era uma base especializada em postais urbanos e depois progressivamente ampliada com outros bancos associados muitas vezes a novos conjuntos incorporados ao acervo, como a coleção Militão Augusto de Azevedo, decisão oportuna que permitiu o crescimento de acervo associado à sua disponibilização a curto prazo para consulta.

A manutenção e ampliação desse conjunto ao longo da década apresentaram um desenvolvimento irregular. A ação de reunião dos diversos conjuntos numa base integrada prolongou-se por grande período e levou num primeiro momento à redução do grupo de descritores utilizados na recuperação; lapsos esses no processo de consolidação que começam agora a ser superados.

Essas duas experiências notáveis não conseguiram estabelecer uma ponte para consulta on-line, via Internet. Se o uso desse novo instrumento de difusão no quadro das entidades paulistanas ainda merece um estudo histórico, que deverá superar com extrema dificuldade o fato de não haver registros consistentes das ocorrências, é possível apontar que serviços de consulta pela Internet não foram efetivamente desenvolvidos, com exceção de acervos bibliográficos como a excepcional interface Dedalus, disponibilizada pela USP há quase 10 anos. 
Experiências recentes ainda merecem avaliação como as desenvolvidas com suporte da Embratel a partir de segmentos dos acervos da Biblioteca Municipal Mário de Andrade (BMMA) e do Departamento do Patrimônio Histórico, ambos os órgãos associados à Secretaria Municipal de Cultura, mais uma vez enfocando o Arquivo de Negativos. É urgente, num quadro maior, estudar as relações entre fotografia e cultura que ocorrem na Internet, aspecto para o qual NENHUMA instituição brasileira (de pesquisa acadêmica a instituições de memória) está orientada e equipada.

Algumas respostas sobre a ferramenta digital

Passemos a tentar responder, ainda que temerariamente, sobre as conseqüências do uso da tecnologia digital, em seu amplo espectro, no âmbito das instituições de memória no contexto paulistano.

A primeira questão aponta para as implicações da transferência de suporte - imagem química para digital - para o estudo da fotografia como documento e artefato museológico.

Tal passagem é necessária e inevitável. Há certamente lucros imediatos, que atendem aos nossos próprios desejos "juvenis" sobre acesso, rapidez e abrangência de recuperação de dados em busca de ferramentas que facilitem (e estimulem) novas pesquisas e abordagens inusitadas. $\bigcirc$ prejuízo evidente diz respeito ao estudo do objeto fotográfico, em especial aquele circulado no século XIX, que demanda exigências específicas como reproduções do verso da imagem, do suporte utilizado, etc. No entanto, essa dificuldade de conhecimento material sempre existiv e reflete a ausência de um campo de ensino mais sofisticado, de museus com coleções que apresentem a diversidade de técnicas e usos daquele período e permitam a experiência visual e sensorial de contato com esses objetos.

Com certeza, a rotina de consulta por meio de monitores, a exemplo da primeira interface gráfica implantada há mais de 10 anos pelo ltaú, sempre será um desafio aos designers. E nesse aspecto pouco se tem discutido sobre os projetos implantados ou as potencialidades disponíveis.

A segunda questão possível diz respeito aos critérios para preservação e abre um leque amplo e de difícil especulação. Numa primeira possibilidade a de utilização de matrizes digitais para guarda - a duplicata sempre terá como parâmetro os processos fotográficos em sua máxima qualidade le com certeza com margem larga de reserva para eventuais desenvolvimentos futuros). É evidente que tais decisões dependem de um conjunto de parâmetros como a infra-estrutura de informática instalada, o volume dos acervos, a relação custo-benefício, aspectos esses que afastam sua aplicação imediata fora da esfera restrita dos projetos experimentais para avaliação de práticas. E aqui, abrindo um espaço, ficará sempre necessário referenciar o longo projeto de digitalização do Projeto Portinari, cujos percalços enfrentados em seus quase 20 anos merecem ainda uma avaliação cuidadosa. 
Quanto à segunda possibilidade, a de geração de matrizes para difusão, existe como comentado anteriormente um conjunto de experiências a ser avaliado, sujeito a decisões sob os mesmos parâmetros. Com a mudança acelerada de estágio tecnológico, aplicações como a do Museu Paulista acabaram revelando em prazo muito curto que a substituição por imagens com especificações mais altas era necessária. Essa demanda implicava novos equipamentos, a custos proporcionalmente menores que os iniciais, e aumento de gastos em recursos humanos, esses sim um novo desafio.

diabo mora nos detalhes

Se o panorama apresentado pode transmitir uma idéia de processo de desenvolvimento com alguma naturalidade, é necessário comentar alguns pontos de dúvida que ocorrem ao longo dessa fase de transição.

$\bigcirc$ uso dos instrumentos digitais abre grandes possibilidades de ação e, obviamente, fascínio e sedução. Esses dois termos subjugaram minha atenção recentemente ao ler o ensaio Composição em branco-e-preto: os panoramas de 360 de Militão Augusto de Azevedo, de autoria de Sérgio Burgi, incluso na segunda edição dos Cadernos de Fotografia Brasileira, editado pelo Instituto Moreira Salles, em janeiro de 2004.

Os panoramas da cidade de São Paulo realizados na década de 1860, atribuídos a Militão, são fascinantes. As reconstituições apresentadas seduzem a todos, do público em geral ao especializado. No entanto, passado o momento de surpresa acredito que esse gesto bem-intencionado tenha gerado um hiperobjeto. Os panoramas resultantes são "maiores e melhores" que os fragmentos originais. Na verdade, as imagens originais não parecem ter sido efetivamente difundidas como panorama. A habilidade expressa na reconstituição vai além da manifestação de perícia e gera um produto final que posto ao lado dos originais os esmaga.

Meu estranhamento le aqui é necessário reforçar sempre a avaliação individual) tem como fundo as implicações que esse hiperobjeto teria sobre a percepção da história da fotografia paulistana pelo grande público. E mais além, sobre a percepção da obra de Militão, que não necessita de reforços para uma avaliação histórica. A imagem distorcida da obra (perdão pelo tom), na verdade a imagem falsa, não induziria a erros o público neófito?

Essa operação de reconstituição seria admissível em outros contextos, em outras ações, talvez como recurso cenográfico, pois seria entendida claramente sob tal perspectiva. Isso é perceptível se compararmos as leituras entre a exposição e o artigo editado.

É possível ir além e discutir operações similares não diretamente relacionadas ao nosso universo, mas que dizem respeito ao investimento simbólico que se realiza nas imagens da vida urbana. $\bigcirc$ gesto publicitário é o foco desse comentário, e sua ocorrência banalizada pode ter conseqüências severas. 
Por exemplo, vejamos a campanha do Shopping Iguatemi para o inverno 2003, veiculada em anúncios de página inteira em jornais diários (muitas vezes nos cadernos culturais). Vê-se uma modelo que posa diante de um fundo infinito. É possível observar o cenário maior em que isso ocorre: um ambiente urbano cercado por altos e antigos edifícios. Alguns leitores podem identificar o local e estranhar o procedimento. Trata-se das torres dos edifícios Martinelli e do Banco do Brasil, porém, deslocadas transversalmente da esquerda para a direita.

Fica a questão, por que utilizar tal estranhamento? Para causar distanciamento? Para evitar identificação? Difícil encontrar uma boa resposta. Nem ao menos questões de orçamento poderiam ser apresentadas como justificativa plena para essa intervenção.

Outro exemplo do gesto publicitário de uso da imagem ocorre em anúncio de página dupla, veiculado em revistas semanais como a edição de Veja de 14/5/2003, sobre o novo lançamento de um modelo de automóvel da Fiat ${ }^{5}$. Lá está o veículo estacionado na Rua 15 de Novembro, em frente ao prédio do antigo Banco Comind, mas o que acontece na esquina ao lado? Ela foi substituída por outro edifício, situado na calçada oposta, o velho prédio do Brasilianische Bank für Deutschland tão conhecido pelas imagens de Guilherme Gaensly.

que explica novamente tal intervenção? Melhorar ou ocultar um determinado aspecto urbano de São Paulo? Afinal qual o conjunto de pessoas que poderia reconhecer essas alterações?

que importa para nós aqui é a banalização do gesto. Retornemos (e façamos um paralelo) a outro evento, também associado ao Instituto Moreira Salles (e não vejam nisso nenhuma crítica institucional, apenas a necessidade de análise de nossos gestos corriqueiros). No caso, observemos o painel de apresentação da exposição São Paulo 450 anos, que se abre para a Avenida Paulista na fachada do edifício da Federação das Indústrias do Estado de São Paulo (Fiesp).

Aqui, o mais novo e significativo acervo de imagens sobre a cidade tem como cartão de apresentação uma montagem que indica a evolução das modestas construções do século XIX rumo ao XX. Ora, essa decisão, que poderia ser justificada pelo desejo de não valorização deste ou daquele fotógrafo, seria a mais adequada como chamariz, como gesto publicitário? Não seria mais coerente para uma instituição dedicada à memória da fotografia evitar tal operação sobre as imagens? Ou, talvez, empregar aqui alguns dos panoramas de Militão reconstituídos digitalmente?

Não questiono leituras possíveis sobre esse painel de abertura, como a ênfase simbólica no aspecto construtivo usualmente associado a São Paulo, valorizando o empreendimento físico em detrimento de outros aspectos, mas apenas a manipulação de imagem com resultado visual irrelevante.

Em direção contrária, é possível identificar intervenções com resultados instigantes. No caso, elas ocorrem pela aproximação bem-vinda de artistas visuais numa leitura de acervos institucionais. É o que realiza o Museu Paulista 
na mostra Olho cíclico, aberta em janeiro de 2004, numa iniciativa inédita proposta pelo grupo curatorial dessa instituição. A apropriação realizada por Gavin Adams em duas obras abre possibilidades de novas abordagens que poderiam estimular o desenho de sistemas de consulta, por exemplo.

Vejamos a obra Animatoscópio, que constitui uma interface multimídia para navegação pela coleção Militão Augusto de Azevedo tendo como elemento de estruturação uma tipologia da construção visual dos retratos. A obra ecoa a estética dos videogames, dos jogos de guerra, como forma de atração do visitante. Constitui nessa solução uma possibilidade a ser desenvolvida em novas séries de obras, mas também como interfaces práticas, em especial para Internet, explorando a sedução dos jogos on-line. A outra obra apresentada por Adams, o vídeo de um minuto, visto em looping, intitulado Ambientes, funde sucessivos retratos realizados no estúdio desse fotógrafo procurando recriar tal espaço.

Essas apropriações, ainda que estimulantes pela abordagem inusitada (e consciente manipulação), não estão porém a salvo da avaliação de suas conseqüências, mas ocorrem em contexto distinto do gesto publicitário, que banaliza irrefletidamente nosso cotidiano, nossa memória.

Referências documentais

$\bigcirc$ conjunto de textos, em qualquer formato, sobre a temática aqui desenvolvida, é extremamente reduzido. Ocorrem em parte como relatos descritivos de sistemas de gerenciamentos automáticos, na forma de manuais operacionais ou registros sumários sobre as coleções tratadas. Apesar disso, decidiu-se pela inclusão de uma primeira relação dessa produção.

Recomenda-se como referência para compreensão de parte do panorama de trabalho das principais instituições de pesquisa em São Paulo relacionadas à temática a leitura da tese de doutorado de Maria Christina Barbosa de Almeida. Por uma rearquitetura dos serviços de informação em arte na cidade de São Paulo. São Paulo, ECA-USP, 1998, il. 364p.

Artigo apresentado em 06/2004. Aprovado em 08/2004. 